\title{
Evidence-based reform of teaching and learning
}

\author{
Melanie M. Cooper
}

Published online: 14 November 2013

(C) Springer-Verlag Berlin Heidelberg 2013

Over the years a great deal of time and attention has been devoted to reform of teaching and learning in chemistry. However, many of these efforts have focused on individual faculty's experiences and intuition, rather than our understanding of how people learn or evidence about the effects of such reforms. For example, while it is widely known that students emerge from our courses with non-scientific ideas about core concepts, the reasons why this happens are often ascribed to the students' lack of ability or work ethic. However, there is emerging evidence that both the traditional pedagogical approach and the structure of the curriculum contribute to this problem. Students must be provided both with a strong foundation on which to build and link new knowledge, and an understanding of what that knowledge will be used for. In order to achieve this we need to rely on the research base and evidence emerging from discipline-based education research (DBER) - a field that combines deep disciplinary expertise with knowledge and understanding of the science of teaching and learning. This paper presents a short overview of these ideas.

\section{Introduction}

The term "evidence-based" is being heard increasingly often in conjunction with education reforms. Gone are the days (or perhaps more accurately gone should be the days) when "reform" was simply a matter of faculty designing new teaching materials based solely on personal opinion, preferences, and experiences. While such an approach may be satisfying both to the faculty (who may be lauded for bringing

M. M. Cooper $(\bowtie)$

Department of Chemistry, Michigan State University, East Lansing, MI 48824, USA

e-mail:mmc@msu.edu innovation to the classroom) and to the students, who typically respond well to enthusiastic and engaged faculty (and to be sure there is nothing wrong with that!), there is little evidence that students emerge from such classes with a better understanding of chemistry or an increased ability to apply their knowledge in new situations. Given the often significant investment made by faculty, a common response to the lack of improvement (assuming it is even recognized) is to assign blame, sometimes to the students themselves, their high school teachers, or perhaps even the educational system.

There are number of factors that influence, and are required for, successful course reform. Perhaps the most important is to recognize that we, as college faculty, are not only educating the next generations of chemists (although most of the students in our classes are not destined to be chemists), we are educating future teachers, who learn their disciplinary content in our classes (rather than through postgraduate training). In a time when scientific literacy is increasingly important, it is time for us to recognize our role in the education system, and as scientists it is (long past) time for us to adopt a more scientific stance when it comes to educational content, practices, and curriculum reform. We must think about how wellestablished models of learning might guide course and curricular design and delivery, and what evidence might be sought that would reveal whether our efforts are effective. That is, what do students really need to learn and what are the "most effective" ways to help students learn it?

Over the past few decades there has been a growing body of work that speaks to how people learn $[1,2]$ and how we might better structure learning experiences, including specifically how students learn science [3] as well as multiplicity of affective components that impact learning [4], and a better understanding of the neural mechanisms that underlie learning [5]. A major problem for those of us interested in incorporating these insights into our teaching (and more generally in course design and evaluation) is that this information and 
evidence come from disparate disciplines, and are often presented in the jargon and the somewhat arcane (i.e., nonchemical) language of those disciplines. Meanwhile, a new field of discipline-based education research (DBER) has emerged. DBER combines a deep disciplinary knowledge with a thorough understanding of the theories and methods used for research on teaching and learning. DBER scholars are often found within the disciplinary departments, and certainly in chemistry there are a growing number of departments who are hiring (and tenuring) faculty whose scholarship lies in the area of chemistry education research (CER).

The recent National Research Council (NRC) report on DBER [6] is a synthesis of what we know about student learning at the college level in various science, technology, engineering and mathematics (STEM) disciplines. The conclusions and recommendations in the report can provide an excellent resource for faculty who are interested in learning more about the research basis for effective education. In addition a practitioner volume will be published in 2014 that will provide a more accessible guide. Here, I provide an even shorter overview of the evidence and models that can serve to guide faculty who are short on time, but who care about teaching and learning.

\section{Evidence-based approaches to teaching and learning}

Knowledge is constructed in the mind of the learner [7]

While this idea may seem either esoteric or obvious, it is worth noting that it often directly contradicts many traditional teaching methods, which suggest that knowledge can be conveyed to students simply by telling them. There is, in fact, a great deal of evidence to support the educational model known as constructivism. For example, the NRC DBER report (Conclusion 6) states: "In all disciplines, undergraduate students have incorrect ideas and beliefs about fundamental concepts." While this may seem self-evident, we might stop and ask ourselves why. Why is it that students emerge from our courses with a wide range of incorrect ideas? One has only to talk to students about their understanding to see that students do not learn exactly what we tell them in lectures, no matter how engaging the presentation. While we might hope that telling students about ideas, showing them how to work out problems, and then sending them away to practice those problems are appropriate methods for teaching chemistry (after all it worked for all us chemists), in fact knowledge cannot be transmitted like this. The truth is that knowledge is constructed by the students and if we do not provide them appropriate opportunities to construct and synthesize their knowledge and skills, we cannot be surprised when their understanding falls short of what we expect.
For example, one of the most persistent, incorrect ideas in chemistry is the belief that chemical bonds release energy when they break. Even after years of instruction it has been reported that about $50 \%$ of students $[8,9]$, including graduate students and postdoctoral scholars, continue to harbor inconsistent ideas about the energetics of bond breaking. Somehow traditional instruction has failed these students; even though they have surely been taught multiple times that bond breaking is endothermic, many have constructed erroneous ideas about this concept. If we as faculty are aware of the presence of these deeply held, difficult ideas, if we understand how they arise, and that they are not the product of a "poor background" or a sign of a student who is lazy or inept, then that can help us in our reform efforts.

The reconstruction of incorrect ideas and concepts to a more scientifically accurate form can be difficult (and occupies a large niche in the research literature) [6]. One thing is clear, the learner must have opportunities to actively construct and try out ideas and skills and receive meaningful feedback if they are to master these often counterintuitive ideas. Merely asking students to recognize the "correct" answer can be highly problematic (although perhaps a good test of memory and motivation). It is quite possible to do well on traditional types of assessments (multiple choice, or rote calculations - even where the work is shown) without actually understanding the concept or skill, and without being able to transfer those ideas to a new situation.

One of the most robust approaches that provide students the opportunity to construct meaning is to provide opportunities for peer learning and teaching $[10,11]$. Socially mediated learning - whether as informal groups during lectures or more structured cooperative learning groups - has been shown to improve learning outcomes $[9,12]$. Providing students with opportunities to discuss the material allows them to organize and sort the information (especially when explaining to others), making retrieval and appropriate use more likely in the future. However, it should be noted that much of the advice provided to faculty about improving their teaching centers around making the instruction more student centered; although these approaches are important, they are clearly not enough.

What students learn must be connected to what they already know and what they are going to learn

Another evidence-supported approach is that of meaningful learning $[13,14]$. Meaningful learning acknowledges that students construct knowledge, but it also recognizes that this knowledge construction must be build on a firm foundation, and must lead somewhere meaningful (to the student). That is, what the student learns must be connected to what the student already knows. Facts and skills that are not cognitively connected to other ideas are difficult to retrieve, and are unlikely 
to be used in new situations (this idea is also referred to as the zone of proximal development [15]). Equally important, this new knowledge must be used in a meaningful way (e.g., in an authentic task) or at least must be perceived as being of use for some future purpose. Otherwise the student may choose not to learn meaningfully, but rather to memorize in a rote or shallow fashion.

In practice there are two instructional activities that can help support students to learn meaningfully:

(a) Understand what students' already know (or think they know) before teaching new material. This is particularly important if new knowledge is presumed to build on existing understanding. Indeed, if a student has a weak or incorrect understanding of the ideas or skills needed to support the new material, it is highly unlikely that they will be able to construct a coherent or correct understanding. The development of misconceptions is a product of a weak foundation, and when left unresolved can only exacerbate the students' fragmented disconnected ideas; it is unlikely that a correct working understanding can be built on such a foundation.

One approach to addressing students' prior knowledge is to ask concept questions that have been specifically designed to reveal "misconceptions" or faulty reasoning. There are a growing number of collections of these items [16, 17], often called concept inventories; however, great care should be exercised in their use (e.g., pre/post testing using the same item may merely test whether the student remembered the correct answer). Once the instructor understands what their students know then the teaching and learning can begin, or as Ausubel wrote: "The most important single factor influencing learning is what the learner already knows. Ascertain this and teach him accordingly" [15].

(b) Be explicit about what the new material is to be used for. If students do not understand why they are learning a topic, it should not surprise us when they choose not to engage with a deeper more robust approach to learning. For example, we found that many students (at all levels) were unable to draw Lewis structures [18], despite being given perfectly clear rules about how to do this. By interviewing students and examining their work, it emerged that students did not know why they were learning to draw these structures (i.e., to help them predict chemical and physical properties). Redesigning the curriculum to stress this point produced significant improvements in student abilities [19].

Meaningful learning requires that attention be paid to both students' prior knowledge and the knowledge goals; therefore, as course and curriculum developers, we must pay attention to the order in which students learn the material. For example, in general chemistry, Chapter 4 is almost always "solutions", even though to understand the structure and behavior of a solution requires a number of complex ideas. Typically, at this point in a course the students have no understanding of bonding or interactions and their associated energy changes. The typical unit on solutions assumes substantial prior knowledge that has been shown to be quite difficult for students and is often incompletely or incorrectly understood. At the same time, it introduces ideas without appropriate context, ideas that are often not returned to for a long time. That is, a typical general chemistry course violates most of what we know about structuring a robust understanding of concepts.

The real lesson from the meaningful learning approach is that effective teaching, measured in terms of student learning, requires a well-conceived presentation of core concepts, sometimes called a learning progression [20,21] (and really it does seem like common sense doesn't it?). We have developed a general chemistry course arranged around such sequences or learning progressions and shown improved outcomes for a number of concepts and skills [22]. While other learning progressions are imaginable, what is clear is that some such progression is a critical component of effective course design.

\section{What counts as evidence?}

When all is said and done, the following questions will remain: How will we know when our reforms are effective? What are the standards of evidence that we will accept? Unfortunately, when dealing with real students in the real world the evidence we obtain may not be as clear-cut as what may be used to base our laboratory experiences on. The instruments we use to measure outcomes (tests and surveys rather than NMRs), the subjects (humans rather than molecules), and the experimental procedures are all less objective than we are used to, but this does not mean that we should be satisfied with merely asking students if they "like" the approach.

\section{What is important to measure?}

The assessment instruments we use should match our goals for student learning. We have to decide what aspects of learning are important? Are we content with students who know facts and algorithms? As you might imagine, it is far easier to develop reliable and valid questions to assess whether students "know" something, or can perform a calculation. However, if we are to improve how and what our students learn, we have to think seriously about the nature of the assessments we use in a course. For example, would we want students to take what they know and use it in new situations? 
If so then we must develop and use assessments that determine whether students can use their knowledge and skills to predict and explain, to construct arguments using data, and to develop and use models. For example, there is strong evidence that asking students "deep explanatory questions" [23] improves learning, particularly if they are given opportunities to explain and revise their answers.

While it is not possible to discuss all the factors that impact student learning in this short paper, I hope that I have convinced you that there are some fairly well-understood reasons why students do not learn effectively in many situations, and that there are evidence-based approaches to improving outcomes. For instructors whose background does not include ideas and practices of chemistry education (i.e., almost all of them), the ideas outlined in this paper can guide your practice. It is no longer acceptable to teach how we were taught, or to ignore the evidence that is accumulating about how to structure more robust teaching and learning activities. While there are literally thousands of research studies that might be used to improve STEM education (including learning outcomes, retention, and improvements in participation by underrepresented groups), what we also know is that change is glacially slow and it is time for that to change.

Acknowledgments The author would like to thank Michael Klymkowsky for helpful suggestions and discussions during the preparation of this manuscript.

\section{References}

1. Bransford JD et al (eds) (2000) How people learn: brain, mind, experience, and school. National Academies Press, Washington DC

2. Mayer RE (2011) Applying the science of learning. Pearson/Allyn \& Bacon, Boston

3. Duschl RA, Schweingruber HA, Shouse AW (2007) Taking science to school: learning and teaching science in grades K-8. National Academies Press, Washington DC

4. Nieswandt M (2007) Student affect and conceptual understanding in learning chemistry. J Res Sci Teach 44:908

5. Rugg MD (2013) Cognitive neuroscience. Psychology Press, New York

6. Singer SR, Nielsen NR, Schweingruber HA (2012) Discipline-based education research: understanding and improving learning in undergraduate science and engineering. National Academies Press, Washington DC

7. Bodner GM (1986) Constructivism: a theory of knowledge. J Chem Educ 63:873

8. Boo HK (1998) Students' understandings of chemical bonds and the energetics of chemical reactions. J Res Sci Teach 35:569
9. Teichert MA, Stacy AM (2002) Promoting understanding of chemical bonding and spontaneity through student explanation and integration of ideas. J Res Sci Teach 39:464

10. Tien LT, Roth V, Kampmeier JA (2002) Implementation of a peer-led team learning instructional approach in an undergraduate organic chemistry course. J Res Sci Teach. doi:10.1002/tea.10038

11. Moog RS, Creegan FJ, Hanson DM, Spencer JN, Straumanis A, Bunce DM, Wolfskill T (2009) In: Pienta NJ, Cooper MM, Greenbowe TJ (eds) Chemists' guide to effective teaching: volume II. Prentice Hall, Upper Saddle River

12. Cooper MM, Cox CT, Nammouz M, Case E, Stevens R (2008) An assessment of the effect of collaborative groups on students' problem solving strategies and abilities. J Chem Educ 85:866

13. Novak JD (1977) A theory of education. Cornell University, Ithaca

14. Bretz SL (2001) Novak's theory of education: human constructivism and meaningful learning. J Chem Educ. doi:10.1021/ed078p1107.6

15. Ausubel DP (1968) Educational psychology: a cognitive view, Ausubel DP. Holt, Rinehart, and Winston, New York

16. Taber K (2002) Chemical misconceptions - prevention diagnosis and cure. Royal Society of Chemistry, London

17. Mulford DR, Robinson WR (2002) An Inventory for alternate conceptions among first-semester general chemistry students. J Chem Educ 79:739-744

18. Cooper MM, Grove N, Underwood SM, Klymkowsky MW (2010) Lost in Lewis structures: an investigation of student difficulties in developing representational competence. J Chem Educ 87:869

19. Cooper MM, Underwood SM, Hilley CZ, Klymkowsky MW (2012) Development and assessment of a molecular structure and properties learning progression. J Chem Educ 89:1351

20. Krajcik JS, Sutherland LM, Drago K, Merritt J (2012) In: Bernholt S, Neumann K, Nentwig P (eds) Making it tangible - learning outcomes in science education. Waxmann, Münster

21. Schwarz CV, Reiser BJ, Davis EA, Kenyon L, Achér A, Fortus D, Shwartz Y, Hug B, Krajcik J (2009) Developing a learning progression for scientific modeling: making scientific modeling accessible and meaningful for learners. J Res Sci Teach. doi:10.1002/tea. 20311

22. Cooper M, Klymkowsky M (2013) Chemistry, life, the universe, and everything: a new approach to general chemistry, and a model for curriculum reform. J Chem Educ 90:1116

23. Pashler H, Bain PM, Bottge BA, Graesser A, Koedinger K, McDaniel M, Metcalfe J (2007) Organizing instruction and study to improve student learning. IES practice guide. NCER 2007-2004. National Center for Education Research, Washington DC

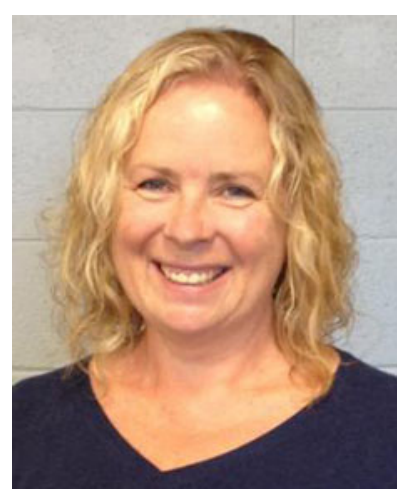

Melanie Cooper is the LappanPhillips Professor of Science Education and Professor of Chemistry at Michigan State University. She received her B.S., M.S., and Ph.D. in chemistry from the University of Manchester, UK. Her research has focused on improving teaching and learning in large enrollment general and organic chemistry courses, and she is a proponent of evidence-based curriculum reform. 